Instructions for authors, subscriptions and further details:

http://brac.hipatiapress.com

\title{
Arte y Vida en Disolución: Aproximación a la Obra de Llorenç Barber
}

Isaac Diego García Fernández ${ }^{1}$

1) Universidad Internacional de La Rioja. (Spain)

Date of publication: October $3^{\text {rd }}, 2018$

Edition period: October 2018 - February 2019

To cite this article: García, I.D. (2018). Arte y Vida en Disolución:

Aproximación a la Obra de Llorenç Barber. Barcelona, Research, Art, Creation, 6(3) 296-321. doi: 10.17583/brac.2018.2695

To link this article: http://dx.doi.org/10.17583/brac.2018.2695

\section{PLEASE SCROLL DOWN FOR ARTICLE}

The terms and conditions of use are related to the Open Journal System and to Creative Commons Attribution License (CC-BY). 
BRAC - Barcelona Research Art Creation. Vol. 6 No. 3, October 2018, pp. 296-321

\section{Art and Life in Dissolution: Approach to the Work of Llorenç Barber}

Isaac Diego García Fernández.

Universidad Internacional de La Rioja. (Spain)

(Received: 11 April 2017; Accepted: 18 June 2018; Published: 3 October 2018)

\section{Abstract}

This article reflects on the nature of the creative act in relation to the everyday world. In opposition to the formalist conception of the artistic work as an autonomous object, during the 20th century various authors tried to spotlight the dialectical relationship established between art and life. Particularly important was John Cage, who started, from Dadaism, a profound transformation in the field of experimental music. His thinking had a great influence on several generations of musicians and sound artists. A case particularly revealing is Llorenç Barber, interdisciplinary artist and composer. Its proposals, which developed outside of the traditional concert rite, intend to dilute the artistic work in its context. These are essentially shared listening situations in everyday environments. From among its creations, the 'plurifocal' concerts for city stand out: gigantic compositions designed for each urban layout, which acquire a dimension of art public. The objective of the musician is to intervene artistically the common space to be returned to the community in the form of collective celebration. Ultimately, through the study of the work and thinking of Barber, this text aims to explore the boundaries between music and life.

Keywords: soundscape, John Cage, Musical Graphism, Public Art, Llorenç Barber

BRAC - Barcelona Researı pp. 296-321 
BRAC - Barcelona Research Art Creation. Vol. 6 No. 3, October 2018, pp. 296-321

\section{Arte y Vida en Disolución: Aproximación a la Obra de Llorenç Barber}

Isaac Diego García Fernández.

Universidad Internacional de La Rioja. (España)

(Recibido: 11 abril 2017; Aceptado: 18 junio 2018; Publicado: 3 octubre 2018)

\section{Resumen}

El presente artículo reflexiona acerca de la naturaleza del acto creativo en relación con el mundo cotidiano. Frente a la concepción formalista de la obra artística como objeto autónomo, a lo largo del siglo XX diversos autores trataron de poner en evidencia la relación dialéctica establecida entre arte y vida. Especialmente relevante fue la figura de John Cage, quien, a partir del Dadaísmo, inicia una profunda transformación en el ámbito de la música experimental. Su pensamiento será enormemente influente en diversas generaciones de músicos y artistas sonoros. Un caso sustancialmente revelador es el del compositor y artista interdisciplinar Llorenç Barber. Sus propuestas sonoras, que se desarrollan fuera del rito de concierto tradicional, pretenden diluir la obra en su contexto. Son, en esencia, situaciones de escucha compartida en espacios cotidianos. De entre sus creaciones, destacan los conciertos "plurifocales" para ciudad, gigantescas composiciones diseñadas para cada trazo urbano, que cobran una dimensión de arte público. El objetivo del músico es intervenir artísticamente el espacio común para devolverlo a la comunidad en forma de fiesta y celebración de lo colectivo. En última instancia, a través del estudio de la obra y pensamiento de Barber, este texto pretende explorar los supuestos límites entre música y vida.

Palabras clave: paisaje sonoro, John Cage, grafismo musical, arte público, Llorenç Barber 
Qué distingue un objeto cotidiano de una obra de arte? ¿Es posible diferenciar sonidos "musicales" de sonidos "no musicales"? ¿Puede existir la música sin contexto? Al interrogarnos acerca de la relación entre el arte y la vida, entre experiencias estéticas y experiencias cotidianas, parece inevitable preguntarse por el origen mismo del arte. Una respuesta posible hallamos en la idea del arte como aspiración trascendente del ser humano, como "necesidad antropológica". Desde el idealismo alemán y el pensamiento romántico del siglo XIX, el arte fue ampliamente reconocido como un acto de trascendencia. El ser humano, en su intento por dar sentido a la vida y enfrentarse a la incertidumbre, habría buscado modelos de perfección que le permitieran pensar en un mundo utópico más allá del propio mundo. En este sentido, la música simbolizaría una ilusión de trascendencia, una manera de controlar y congelar el flujo inexorable del tiempo. Como indica John Paynter (1999),

Aunque por un lado parece que las artes representan lo no permanente (en la medida en que la función de los artistas no es la de establecer un statu quo sino la de arriesgarse y encontrar nuevas formas de expresión que correspondan con nuevos modos de percepción), no obstante, es través de las estructuras artísticas que vislumbramos un tipo distinto de existencia, exterior al constante flujo de tiempo y espacio. Dichas obras parecen controlar las dimensiones espacio/tiempo. (Paynter, 1999, p. 17)

Desde esta perspectiva, el arte se concibe como un orden utópico que nos permite trascender nuestra realidad cotidiana. Como indicara Schloezer en su intento por despojar a la música de su dimensión sentimental, "el compositor produce en el tiempo una cosa que, por disponer de sentido, se vuelve intemporal. Organizar musicalmente el tiempo significa trascenderlo". (Schloezer, 1961, p. 28) Este proceso de trascendencia provoca inevitablemente la separación del objeto de su función cotidiana para colocarlo en un plano ontológico distinto. En el caso de la música, el objeto descontextualizado, despojado de materia, es el sonido. También la partitura, como representación gráfica, sería un intento por concebir estructuras de tiempo "fuera del tiempo". Como acertadamente señala Miriam Arroyave (2013),

El tiempo "aplanado" de la partitura es un tiempo objetivo e independiente de cualquier situación subjetiva temporal, un tiempo lineal, unidireccional y homogéneo. El tiempo-orden del escrito 
musical es diferente al tiempo-devenir de la percepción, dos tiempos que se fundan sobre dos ontologías diferentes, sin la unión de las cuales no se puede pensar el tiempo. (Arroyave, 2013, p. 89)

La musicología tradicional, creada en el seno del Formalismo del siglo XIX, ayudó en gran medida a perpetuar la concepción de las obras musicales como estructuras autónomas, con valor y significado propios, fuera de su contexto. Desde esta perspectiva, la música, como objeto de estudio científico, posee significados propios más allá del mundo sensible. Para ello, la partitura se convierte en el único objeto de estudio. La música, desde el prisma formalista, es una noción idealizada de sonido sin tiempo donde no tiene cabida lo "extramusical", donde no existe el ruido, ni el sudor ni la materia. La música, por tanto, es arrancada despiadadamente de su contexto ontológico para vivir fuera del mundo cotidiano. Como sentencia el compositor Iannis Xenakis (1982),

Todo hecho sonoro puede ser considerado como una función lógica, en el sentido de la teoría de conjuntos o de la lógica simbólica, del conjunto de vectores del espacio vectorial (...) Así, una composición musical puede ser vista, en primer lugar, como operaciones y relaciones fundamentales, independientes del tiempo, es la llamada estructura lógica o algebraica fuera del tiempo. (Xenakis, 1982, p. 28-29)

Siguiendo la línea de la Modernidad, las vanguardias de la música europea herederas del atonalismo vienés condujeron la creación musical a planteamientos cada vez más racionalistas. De la mano del serialismo integral, la música se convierte en un espacio de especulación donde no importa tanto cómo suena la música, sino cómo está construida. Todo ello explicaría, en gran medida, el enorme impacto que el pensamiento de John Cage produce en el seno de la vanguardia europea. El concepto de la autonomía de la obra de arte ya había sido fuertemente criticado por el Dadaísmo, al defender que el verdadero arte de la modernidad es inseparable de la vida. En 1922 Tzara afirmaba que en el arte no existe lo bello y verdadero, no tiene valores universales, no es la manifestación más preciosa de la vida, la vida real es más interesante (Tzara, 1922).

Los planteamientos de Cage, que entroncan claramente con el Dadaísmo de Duchamp, nos obligan a cuestionar de nuevo la supuesta dualidad establecida entre el arte y la vida, entre la vivencia cotidiana y la vivencia estética. El propio Cage declara: "Sí, en este punto, decimos: ¡Sí! Yo no 
discrimino entre intención y no intención, la dicotomía, sujeto-objeto, artevida, etc., desaparece" (Cage, 1961, p.14).

En el prólogo de la edición al castellano de Escritos al oído de John Cage, indica Pardo (1999),

Este rechazo del yo se presenta al mismo tiempo, como rechazo del mundo dualista que opera la distinción entre sujeto y objeto. Por ello, la música de Cage borrará las distinciones y tratará de colocar al oyente en situaciones en las que no pueda darse esa dualidad. La actividad del compositor y la del oyente se fundarán en aceptación. La aceptación supone un nuevo modo de ser en el mundo. El rechazo a la teleología del arte y del hombre. Las consecuencias que se derivan de esta posición serán la desaparición de la noción de obra y la indistinción entre arte y vida. (Pardo, 1999, p. 15)

El proceso de disolución entre sujeto y objeto obrado por Cage exigiría, por tanto, la irrupción de la cotidianidad en el acto artístico mismo. Así, la distinción entre sonidos musicales y no musicales no sería más que el resultado de un acto arbitrario y discriminatorio, es decir, la consecuencia de un proceso cultural. En este sentido, García (2011) argumenta,

Para Cage, la diferenciación entre el ruido no intencionado del entorno cotidiano y el sonido intencionado de la música no es más que un prejuicio mental, y ambos podrían ser incorporados en el proyecto compositivo como subespecies, digamos, de un mismo sonido arquetípico. Esta transgresión a cualquier distinción entre el ruido y el sonido musical, referente directamente a un cuestionamiento crítico entre el ruido y el sonido musical, refiere directamente a un cuestionamiento crítico entre la experiencia cotidiana y la artística, que apunta por extensión tanto a las fronteras entre la vida y el arte, como al espacio en el que ésta primera tiente lugar. (García, 2011, p. 157)

El azar primero, y la indeterminación a través del grafismo musical después, serán los medios a través de los cuales Cage comience a diluir los límites entre vida y arte. Esto le conducirá al happening y al evento como fiesta, en los cuales los acontecimientos sonoros y no sonoros se superponen y suceden dentro de marcos temporales establecidos previamente. De modo similar a Fluxus, en España el grupo Zaj desarrollará su actividad desde 1964 con planteamientos muy similares a los de Cage. Tanto Zaj como Fluxus, en una evidente declaración de intenciones, darán comienzo a sus actividades con obras de Cage. La primera obra del primer evento de Zaj será, precisamente, 4'33'. Este colectivo, creado por Juan Hidalgo, Ramón Barce y Walter 
Marchetti, centrará su actividad en diversas manifestaciones como las músicas de acción, la performance, el mail-art y la poesía visual.

\section{La Irrupción de Llorenç Barber}

En 1970 el compositor Llorenç Barber entrará en contacto con las ideas de John Cage a través de la lectura de Silence, y con el grupo Zaj mediante Ramón Barce. Estos dos acontecimientos le abrirán un nuevo mundo de posibilidades sonoras y conceptuales, que le animará a abandonar su carrera como pianista profesional, al tiempo que lo alejará definitivamente de las corrientes de la vanguardia académica europea. Como indica López Cano (1997),

De este modo, negándose a caer en la tentación de las vanguardias oficiales de dogmáticas escuelas monolíticas, Llorenç Barber opta por construir un universo creativo personal que lo mismo incorpora azar, el gesto, la acción, el grafismo o la indeterminación, que la neotonalidad o la contemplación de la escritura minimal, algunas veces repetitiva, otras, las más, heterorrepetitivas. (López Cano, 1997, p. 22)

Desde entonces, los intereses creativos de Barber se asientan sobre los límites difuminados entre vida y arte, o al menos en una clara voluntad por cuestionarlos. A partir de la influencia del minimalismo anglosajón y de las propuestas de improvisación colectiva desarrolladas por Cornelius Cardew, junto con el universo abierto por Cage y Zaj, Barber promoverá distintas iniciativas de arte colaborativo y multidisciplinar. Surgen así los colectivos Actum (1973) y Taller de Músicas Mundanas (1978). Durante esta etapa, Barber desarrollará un grafismo musical deliberadamente naíf, cuya misión es propiciar una expresión sonora y gestual rica y espontánea. De este modo, empleará una escritura sencilla e intuitiva que ayude a articular los eventos participativos. Desde esta perspectiva, la partitura ya no es un espacio de especulación de un tiempo fuera del tiempo, ni una barrera simbólica entre músico profesional y no profesional, sino una sencilla herramienta que permite la articulación de sonidos y acciones dentro de un espacio temporal y espacial compartido. Esta concepción de la escritura musical evidencia claramente una ruptura con gran parte de las corrientes de música de vanguardia europea, donde la partitura tiende más bien hacia una constante tecnificación.

Desde principios de la década de los ochenta, Barber dará otro paso relevante al plantear sus eventos en enormes espacios urbanos y rurales. Así, 
la música abandona el auditorio y se expande hacia los espacios cotidianos. En esta segunda etapa Barber iniciará sus investigaciones en torno a la campana como instrumento organizador de eventos sonoros colectivos. Ello dará lugar tanto a sus conciertos plurifocales de ciudad, como a sus eventos en espacios naturales. Sin perder su dimensión visual, aquí la partitura tendrá la clara función de organizar acontecimientos sonoros en el tiempo. Barber emplea diversos tipos de notación, donde encontramos desde partituras generativas y esquemáticas, hasta otras de naturaleza topográfica. Si la partitura tradicional organiza los sonidos de un modo lineal en un eje de coordenadas cartesianas, las partituras de Barber permiten habitar el sonido en el espacio colectivo. Como en el caso de Cage, el grafismo musical introduce un grado de indeterminación que niega la obra como especulación atemporal.

\section{El Evento como Disolución: Actum y el Taller de Música Mundana}

De manera similar a como hace Zaj en Madrid desde mediados de la década de los sesenta, Barber lleva a Valencia, su ciudad, diversas manifestaciones estadounidenses de música experimental, como los minimalismos repetitivos de Steve Reich y Phillip Glass, la drone music de Lamonte Young, o las partituras gráficas de Cage y Earle Brown. Precisamente, el grafismo musical desarrollado por la Escuela de Nueva York será una de las líneas de investigación más relevantes en la poética de Barber en estos primeros años. Barber y Palacios (2009) señalan respecto a estos inicios,

El muy imperfecto "solfeo" del pasado (...) se agilizaba y se deja acompañar de visuales llamadas. Y esto debido al surgimiento de "otras" maneras de pensar y formular el sonido; nuevas fuentes sonoras (...); una relación del intérprete no con el "compás”, sino con el tiempo cronométrico, y nuevos parámetros que organizar, antes puramente adjetivos y dejados de transmisión oral: mil maneras "otras" de atacar, persistir, variar y dar fin a cada uno de los singulares sonidos, racimos de sonidos o gestos de una pieza o propuesta para realizar. (...) En muchos casos la partitura gráfica adquiere una "autonomía sugestiva y visual" que tiene difícil traslación, o incluso nulo interés en su aquel sonoro. En efecto, muchas partituras son sólo propuestas de acción (...). Otras son pura imagen poética. (Barber y Palacios, 2009, p. 31)

Un ejemplo muy temprano es Homenaje en “ $D$ ” (1971). La pieza, de corte claramente minimalista, se articula mediante módulos, de forma similar a 
como lo hacen algunas obras de Earle Brown o a las esculturas de Alexander Calder. Para ello, Barber emplea una serie de células, que el intérprete puede recorrer libremente. No existe, por tanto, ningún orden preconcebido para estos materiales, excepto para los puntos de partida y llegada. A diferencia de las partituras convenciones, aquí el tiempo no se organiza de un modo unidireccional, sino que se plantea en forma de obra abierta. La pieza, que oscila constantemente sobre la nota re, posee una clara identidad sonora, al tiempo que siempre es distinta en sus combinaciones modulares (véase Imagen 1).
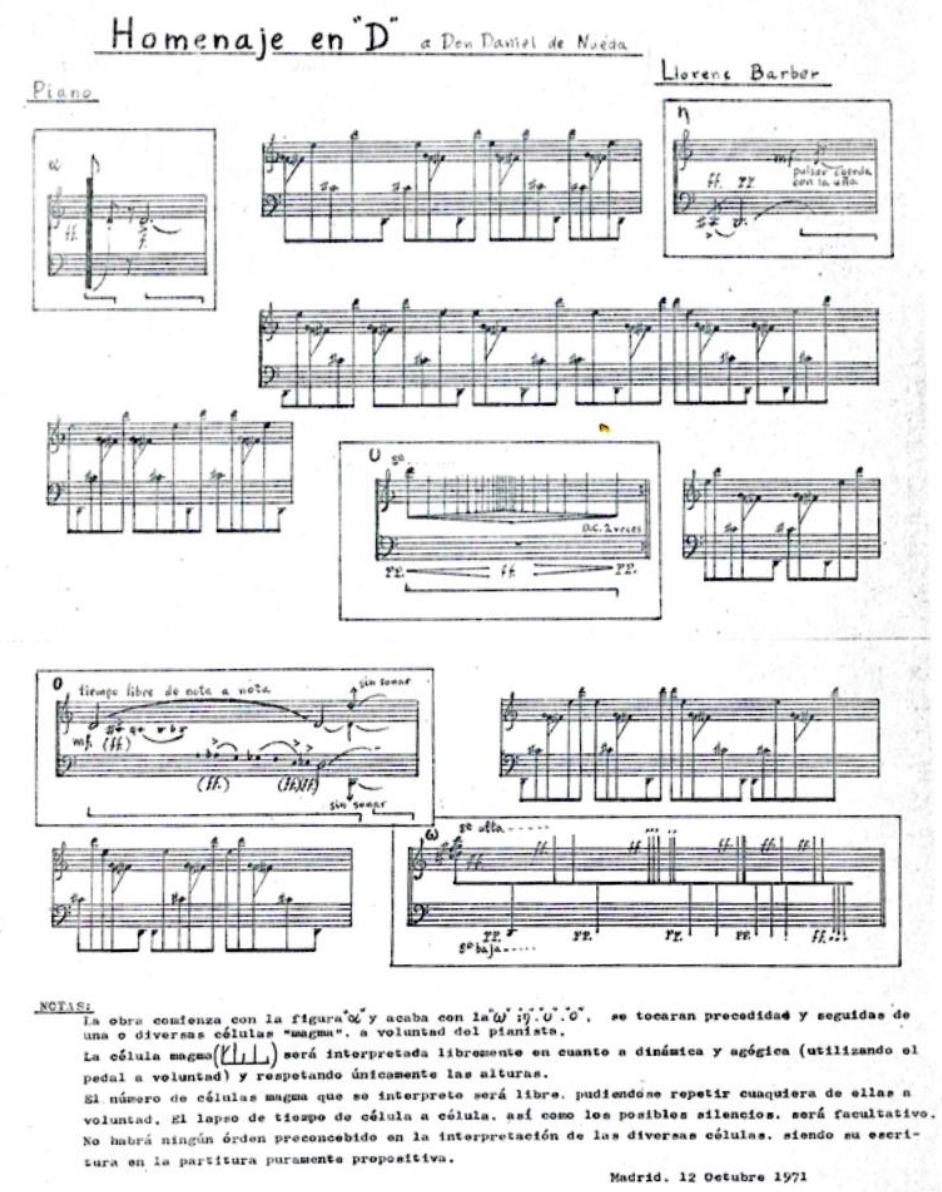

Imagen 1. Llorenç Barber. 1971. Homenaje en “ $D$ ”. 
A partir de estas primeras experiencias, Barber promueve la creación en 1973 del grupo Actum. En la formación del grupo también fue decisiva la aportación de otros nombres, como J. Ll. Berenguer, Amadeo Marín, Ximo Moreno, Jorge Francés y Mari Arnanz, entre otros. Este colectivo de artistas interdisciplinares, que toma posiblemente la Escuela de Nueva York como modelo a seguir, fundamentó su actividad en torno a la constante colaboración entre artistas de distintas áreas creativas, tanto profesionales como amateurs. Desarrollaron para ello músicas minimalistas de carácter diatónico, deliberadamente no disonantes ni atonales; no en situación de concierto, sino de modo integrado en forma de evento. Se trataba generalmente de piezas muy sencillas en su concepción y en su interpretación, de modo que músicos y no músicos pudieran compartir experiencias sonoras abiertas y ricas. De forma similar a como sucedió en el contexto de John Cage, el grafismo musical fue un perfecto vehículo para expresar el sonido, el gesto y el azar.

Dentro de estos eventos, cada participante proponía sus propias piezas y acciones. Uno de los ejemplos más representativos de esta época es Love Story for yu (1975), composición de Llorenç Barber en colaboración de la pianista María Escribano. La partitura se compone de 49 casillas, que el intérprete puede recorrer de formas diversas a partir de unas instrucciones detalladas en una página aparte. El material musical de cada casilla combina diversos tipos de notación, como grafía convencional, dibujos, onomatopeyas, grafías abiertas, etc., para expresar sonidos y gestos cotidianos. Más allá de las infinitas posibilidades sonoras que la partitura sugiere, en esta obra hay una clara intención de alcanzar una plasticidad visual. En este sentido, una posible fuente de inspiración fue el italiano Sylvano Bussotti (1931), cuyas ingeniosas innovaciones notacionales tuvieron una gran repercusión en aquellos años. Otra pieza relevante es Quod tibi mayis relectabilis (1975). La partitura está formada por trece láminas. Cada una de ellas presenta un diseño visual donde combina grafías convencionales con otros recursos gráficos, como letras, dibujos y caligramas. A lo largo de esta pieza el compositor sólo emplea tres alturas: re, la y mi. Se trata, por tanto, de una obra de corte minimalista, que visualmente nos acerca a la poesía visual o concreta desarrollada en esos años por diversos poetas experimentales, como, por ejemplo, Joan Brossa o José Luis Castillejo (véase Imagen 2). 


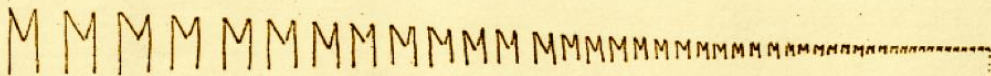

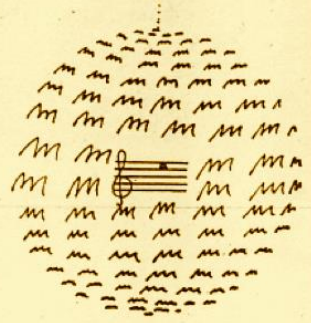

Imagen 2. Llorenç Barber. 1975. Quod tibi mayis relectabilis.

En líneas generales, la mayoría de las partituras desarrolladas por Barber durante su etapa en Actum contienen grafías abiertas y flexibles, que sirven de estímulo visual para que los intérpretes puedan improvisar tanto sonidos como acciones. Se trata en su mayoría de propuestas cuya forma no es cerrada, sino abierta. Los intereses del compositor se proyectan claramente sobre el proceso, más que en su posible resultado final. Del mismo modo que en el happening cagiano la distinción entre vida y arte alcanza su máxima expresión, los eventos multidisciplinares de Actum suponen una clara intención por diluir los límites entre creador e intérprete, entre músico y no músico, entre obra y acto cotidiano.

Otro aspecto relevante de las iniciativas de Actum es su carácter participativo. Se trata, sin duda, de una de las pocas manifestaciones de música experimental participativa desarrollada en España en la década de los setenta. Tampoco los referentes internacionales abundan. Entre ellos, posiblemente la Schatch Orchestra de Cornelius Cardew sea la más representativa. Igualmente podrían citarse algunos de los planteamientos desarrollados por Fluxus, aunque tal vez desde una visión más burlesca. En este sentido, es especialmente revelador aquel cartel de Fluxus que rezaba: “FFLUXUSORCHESTRA INTERPRETA 20 ESTRENOS MUNDIALES! La Monte Young dirige una orquesta de veinte instrumentistas inexpertos" 
(Nyman, 2006, p. 128). Tanto en Fluxus como en las propuestas de Cardew, el grafismo musical fue un mecanismo fundamental para permitir este carácter participativo. Como indica Buj (2015), “abolir la jerarquía entre intérprete profesional y amateur, entre músicos y "no-músicos", ha sido, en ocasiones otra de las motivaciones de los compositores para la creación de partituras gráficas" (Buj, 2015, p. 280).

Fuera del ámbito del colectivo Actum, aunque aún dentro de este periodo inicial, Barber compone la pieza titulada Intus (1980) para el Grupo LIM (Laboratorio de Interpretación Musical). De corte caligramático, la obra consiste en la superposición de células que se repiten sobre una nota pedal. Una vez más, los materiales sonoros son claramente diatónicos; aunque lo más llamativo e interesante de la obra es posiblemente su impacto visual. La partitura, cuya configuración adopta forma de árbol, imposibilita además cualquier tipo de lectura lineal (véase Imagen 3).

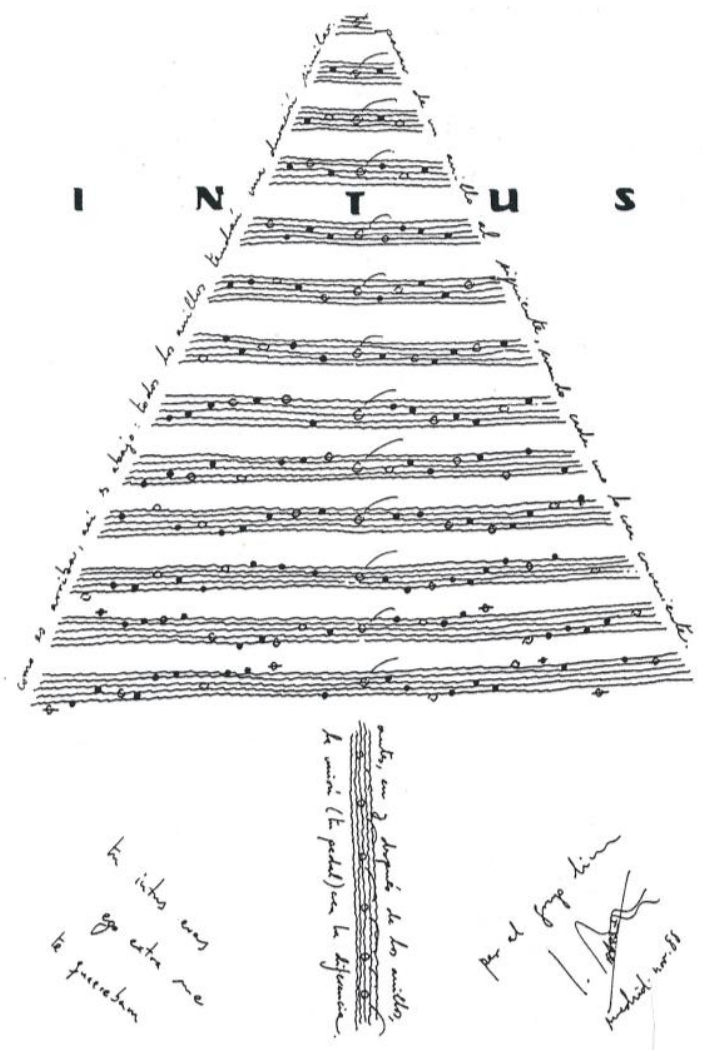

Imagen 3. Llorenç Barber. 1980. Intus. 
Igualmente significativa es Sambori (1978), acción donde se acota un espacio abierto a modo de terreno de juego. Así, las acciones azarosas y cotidianas que suceden en este espacio (como el paso de transeúntes, coches, animales, etc.) se convierten en una suerte de partitura viva que los intérpretes hacen sonar mediante una serie de instrucciones. Si la obra se realiza en un espacio cerrado, el lugar se acota, de modo que, a ojos de los intérpretes, el público es la partitura. Barber estrena Sambori en el festival Music/Context de Londres con dos versiones, una para automóviles y otra para pájaros. Precisamente en este viaje a Londres, Barber entra en contacto con las ideas del canadiense Murray Schafer, lo que le lleva a crear el Taller de Música Mundana, propuesta de creación colectiva en espacios cotidianos (al aire libre, en contacto con animales, etc.). Así, la idea de paisaje sonoro desarrollada por Schafer, incita a Barber a salir definitivamente del auditorio (espacio descontextualizado de la vida cotidiana) y se lanza a la conquista de los espacios públicos. El objetivo es llevar el arte a la calle. Esta iniciativa será el germen de sus conciertos plurifocales en espacios abiertos. Explica el propio Barber (1997):

Este mismo año cree el Taller de Música Mundana, un grupo de sonantes dispuesto a concebir una música, no de culo sino de frente al mundo que vivimos. Al constatar que una calle o una ciudad no suena de forma idéntica a otra, el Taller se hacía la siguiente pregunta: ¿por qué no estudiar, transformar y diseñar el entorno de nuestro hábitat? (...) El artista (el músico) no es un onanista ajeno a la cotidianidad, el concepto de música no es sólo plural sino más todavía, se ha expandido lo suficiente como para proponerse como tarea primordial el hecho de re-escribir el sonar del entorno ya mayoritariamente urbano. (Barber, 1997, p. 28)

\section{De las Campanas al Paisaje Sonoro: el Contexto como Obra}

Había un sonido que dominaba una y otra vez el rumor de la vida cotidiana y que, por múltiple que fuese, no era nunca confuso y lo elevaba todo pasajeramente a una esfera de orden y armonía: las campanas. (Huizinga, 2005, pp. 14-15)

A comienzo de la década de los ochenta se produce un suceso vital en el devenir artístico de Barber: el descubrimiento de las campanas. El súbito interés por este instrumento se produce de modo fortuito. Como relata el 
propio Barber: “(...) un día, buscando una salida de humos para mi estufa, me topé con unas piezas metálicas en forma de ovni y con unas resonancias maravillosamente parecidas a las de las campanas" (Barber, citado en López Cano, 1997, p. 23). No se trataba estrictamente de campanas, sino de unas estructuras en forma de plato invertido empleadas para construir bombonas de gas. Resulta especialmente revelador que su interés por el sonido de la campana se produzca a partir de un gesto tan cotidiano como hacer sonar un objeto de nuestro entorno diario. Relata Barber (1997),

(...) aquellos hierros encontrados me sonaron a música celestial: golpeando sus bordes mediante baquetas adecuadas, sonaban y resonaban como campanas lejanas, de reloj, imponentes campanones catedralicios, tibetanas, (...) Todo un mundo de ancestros sonoros se hacía presente con sólo tratarlas adecuadamente. (...) Todo ello cambió mi vida de músico, también mi concepto de composicióninterpretación-improvisación, relación con el espacio, con el público, con los contextos connotativos del sonar. (Barber, 1997, p. 28)

Tras hacerse con varias de estas pseudo-campanas, Barber construirá su propio campanario portativo. Al toque de estos metales unirá su voz difónica (que aprende de Takeisha Kosugui y Charlie Morrow) y una técnica especial para hacer sonar los parciales de las campanas mediante la cavidad bucal. La fusión de la voz difónica junto con el sonido de la campana y sus respectivos armónicos le llevará a perfeccionar una técnica bautizada por él mismo como "linguofarincampanología". En sus solitarios conciertos para voz y campanas, intérprete e instrumento parecen fusionarse en un discurso tímbrico a múltiples voces. Una vez más, la pretensión -de ecos cagianos- por diluir la dualidad sujeto-objeto (vida-arte) se hace presente en la obra de Barber (véase Imagen 4).

Para este tipo de obras Barber desarrolla un tipo de notación de carácter nemotécnico que le permita planificar estas improvisaciones dirigidas. Para ello, seguirá usando grafías abiertas, en las que las alturas y el ritmo no están completamente definidos, sino sugeridos globalmente. También será muy habitual el empleo de anillos, pequeñas estructuras que se repiten y que se señalan con corchetes. Otro aspecto que resultará familiar en las partituras de Barber será la incorporación de instrucciones para describir acciones. En líneas generales, puede afirmarse que los diversos recursos desarrollados en su escritura le posibilitarán el desarrollo de una poética de corte minimalista repetitivo y diatónico, donde la indeterminación y las acciones siguen estando muy presentes. Dentro de esta producción, hallamos algunos interesantes y 
bellos ejemplos, como Filoflamencampanero (1984), De Hypnerotomachia sonoris (1992), A nonsense talk of o bells (1994) o Musica speciosa (1997), entre otros (véase Imagen 5).

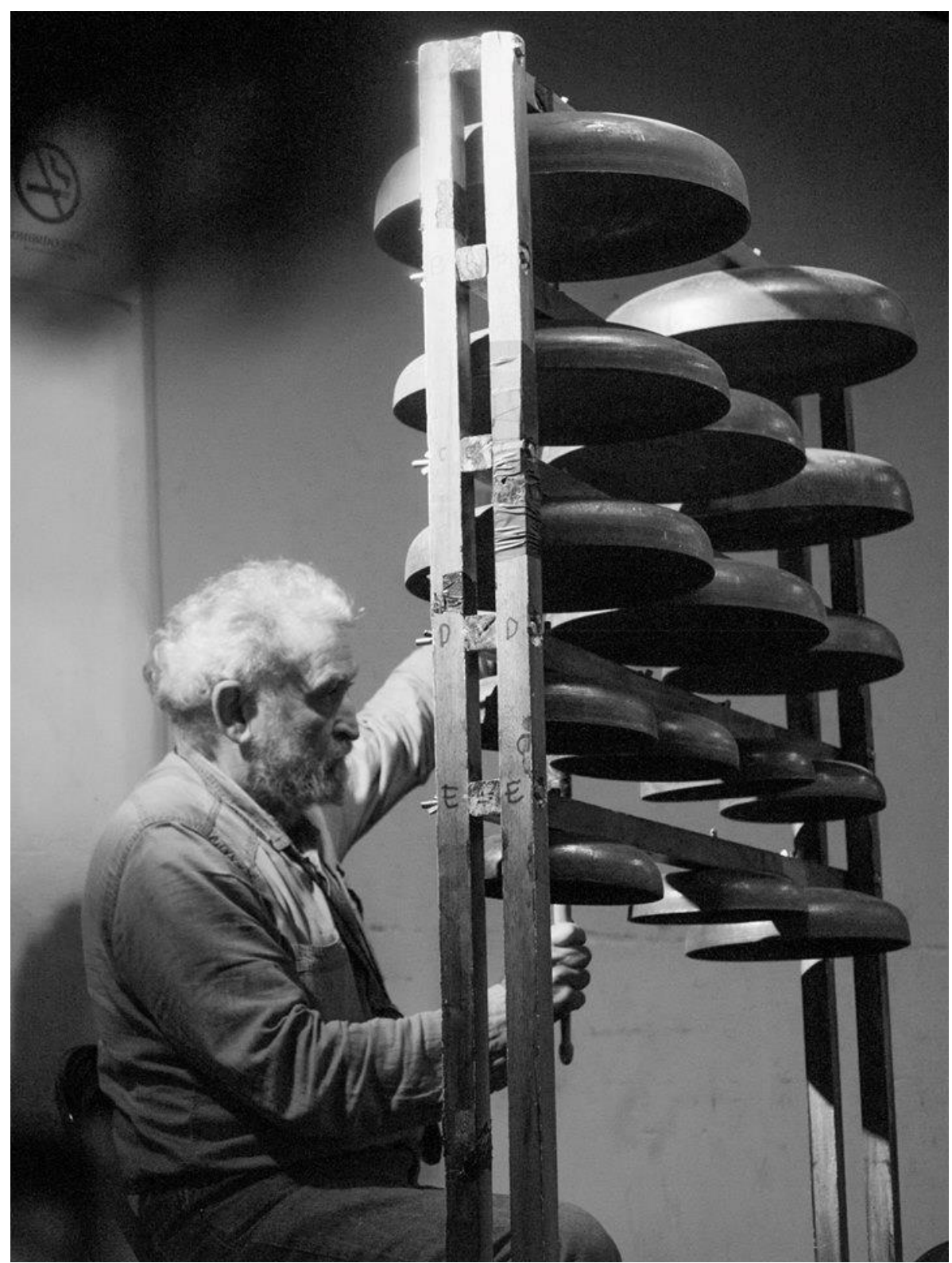

Imagen 4. Fotografía campanario portativo. 


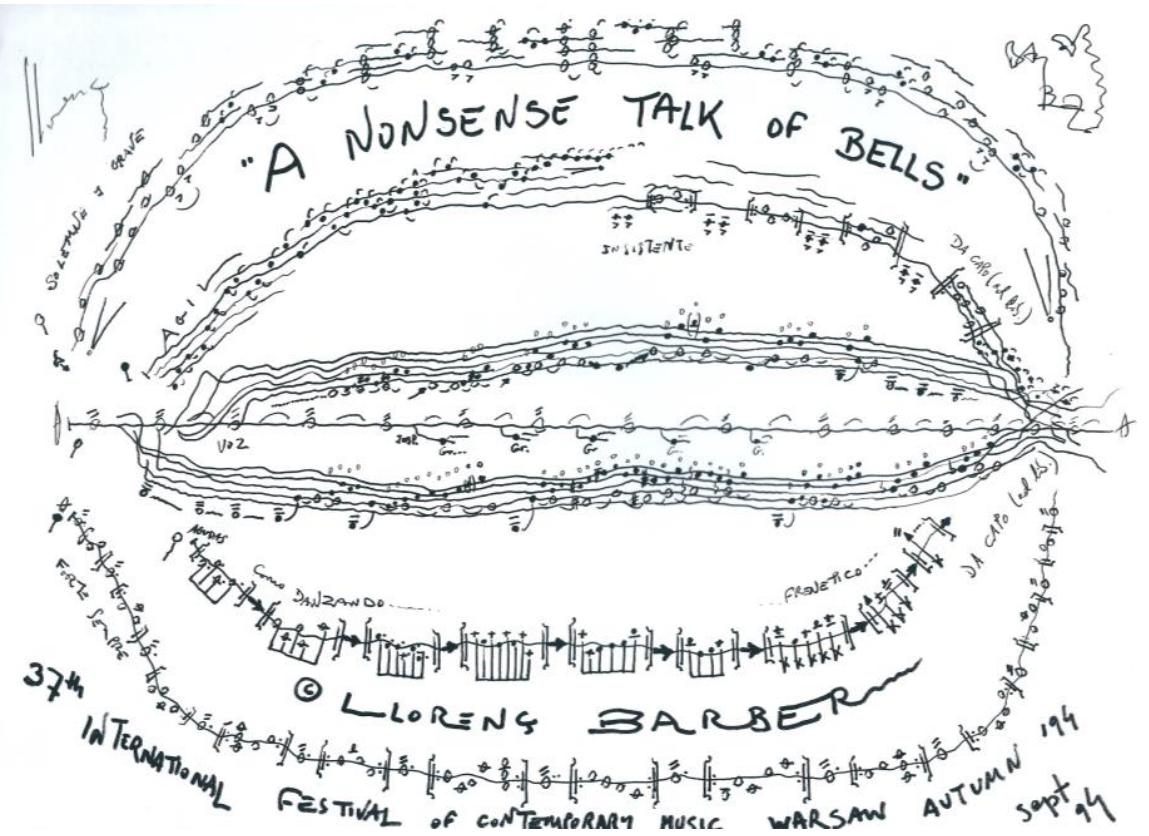

Imagen 5. Llorenç Barber. 1994. A nonsense talk of o bells.

Paralelamente a su trabajo para voz y campanario portativo, Barber desarrollará una intensa labor de investigación sobre las campanas con el antropólogo y experto campanero Francesc Llop i Bayo. Esta labor no se centrará únicamente en el estudio de aspectos técnicos, sino que se supondrá una profunda reflexión acerca de sus implicaciones históricas y antropológicas. Como indica Schafer (2013),

la señal sonora más destacada dentro de la comunidad cristiana es la campana de iglesia. En un sentido muy genuino define a la comunidad, ya que la parroquia es un espacio acústico, circunscrito por el registro de la campana de iglesia. Ésta produce un sonido centrípeto, atrae y une a la comunidad en un sentido social, de la misma manera que acerca al hombre a Dios. En el pasado, a veces, había adoptado asimismo una fuerza centrífuga cuando servía para espantar a los malos espíritus. (Schafer, 2013, p. 86)

Sin duda, el sonido de la campana de iglesia forma parte de la memoria colectiva de una comunidad. Se trata de un elemento cotidiano presente en el espacio sonoro compartido. Forma parte de las principales celebraciones sociales, avisa de inminentes peligros (como incendios y otras catástrofes 
naturales) y anuncia fielmente el transcurso del tiempo. Además, su alcance acústico delimita la comunidad, pues representa una suerte de perímetro invisible. Con el tiempo, el simbolismo cristiano de la campana ha disminuido (o incluso desaparecido), pero continúa siendo un nexo identitario de primer orden.

A las dos funciones que indicaba Schafer (2013), que él denomina centrípeta y centrífuga, habría que sumar una tercera: la funeraria. Juntas, las tres funciones conforman el famoso lema que aparece inscrito en muchas campanas de bronce: Vivos voco. Mortuos plango. Fulgura frango (Convoco a los vivos. Lloro a los muertos. Alejo a las tormentas). Precisamente, y como resultado de una profunda reflexión, esta frase latina dará nombre a sus tres primeros conciertos de ciudad, todos ellos realizados en 1988:

I. Vivos voco (Ontinyent, Valencia, 6 de enero)

II. Mortuos plango (Valladolid, 4 de junio)

III. Fulgura frango (Salamanca, 9 de julio)

A partir de estos tres eventos, Llorenç Barber llevará a cabo multitud de obras plurifocales para ciudad por todo el mundo. Solo entre 1988 y 2002 hay registrados más de 130 conciertos (número que sigue creciendo hasta la actualidad). Entre estas composiciones, cabe destacar las realizadas para las ciudades de Valencia, Sevilla, Madrid, Puebla, Innsbruck, La Habana, Lisboa, Copenhague, París, Londres, Berlín, Salzburgo, Rio de Janeiro, Buenos Aires, Roma, Lyon, York, Quito y un largo etcétera.

Estas composiciones, siempre creadas exprofeso para cada situación, se planifican a partir de los campanarios de la cuidad y de las características del espacio urbano. Como indica López Cano (1997), "los ciudadanos conciertos de campanas son descomunales sinfonías de campanarios donde ciudades enteras suenan al compás de precisas partituras minimales" (López Cano, 1997, p. 13). Sin embargo, estos conciertos incorporan además otros sonidos cotidianos de la cuidad (algunos de ellos móviles), como sirenas de barcos, automóviles sonoros en movimiento (coches y motos, ambulancias, camiones de bomberos, etc.), fuegos de artificio, agrupaciones musicales de todo tipo (como coros, bandas y rondallas), etc.

En los conciertos de ciudad, el espacio urbano, lugar común y cotidiano, es tanto el auditorio como el propio instrumento. Es la ciudad la que suena y reverbera. Ello supone un desbordamiento del concepto de creación musical, pues resultaría imposible concebir la obra como algo separado de su contexto. Así, el contexto se convierte en la propia obra. Nuevamente, el paralelismo 
con Cage es evidente. Del mismo modo que Cage va del happening al circo, Barber va del evento a la fiesta. El propio Barber (1985) apunta acerca de las obras para circo de Cage,

La fiesta necesita espacio, la mayor cantidad de espacio para que puedan convivir interpretándose sin obstruirse la mayor cantidad de sonidos y no sonidos [...] Como en el amor, la fiesta es gratuidad. La tarea de Cage dejará de ser musical para ser social: y se limitará a facilitar procesos que ayuden a transformar la vida cotidiana en una serie de experiencias donde todo ocurra como en la naturaleza. (Barber, 1985, p. 65)

Ello conlleva además una redefinición del tradicional papel de compositor. El propio Barber renunciará a su rango de compositor, para autobautizarse como "propositor" o maestro de ceremonias. Si la función del compositor es crear estructuras fuera del tiempo, el "propositor" nos invita a vivir y experimentar situaciones de escucha. A lo largo de esta vivencia sensorial compartida, el maestro de ceremonias nos propone una visión renovada de nuestro propio espacio cotidiano, y nos ayuda a escucharnos con oídos renovados.

\section{Notación Musical: Topografía del Contexto}

Para la creación de estas gigantescas obras, el compositor emplea dos clases de partitura. El primer tipo es de carácter topográfico, ya que describe los espacios y sus características, así como los movimientos de los intérpretes y los recorridos del sonido, entre otros aspectos. Un ejemplo muy temprano de este tipo de notación es Monte tallado (1984), donde el plano de la iglesia es la propia partitura. En ella, se insertan una serie de números que indican la cantidad de veces que debe ser tocada cada una de las cuatro campanas. En composiciones posteriores, Barber incorporará además los desplazamientos de los intérpretes. Un caso muy representativo descubrimos en la célebre composición Alberomundo (1995), obra plurifocal para diez bandas móviles y un grupo de percusión fijo. La pieza fue compuesta expresamente para la plaza de toros de Alicante. Aparte del guion general de la obra (que es de carácter esquemático), el compositor describe detalladamente en la partitura cada uno de los desplazamientos de las distintas bandas a lo largo de la obra (véase Imagen 6). 


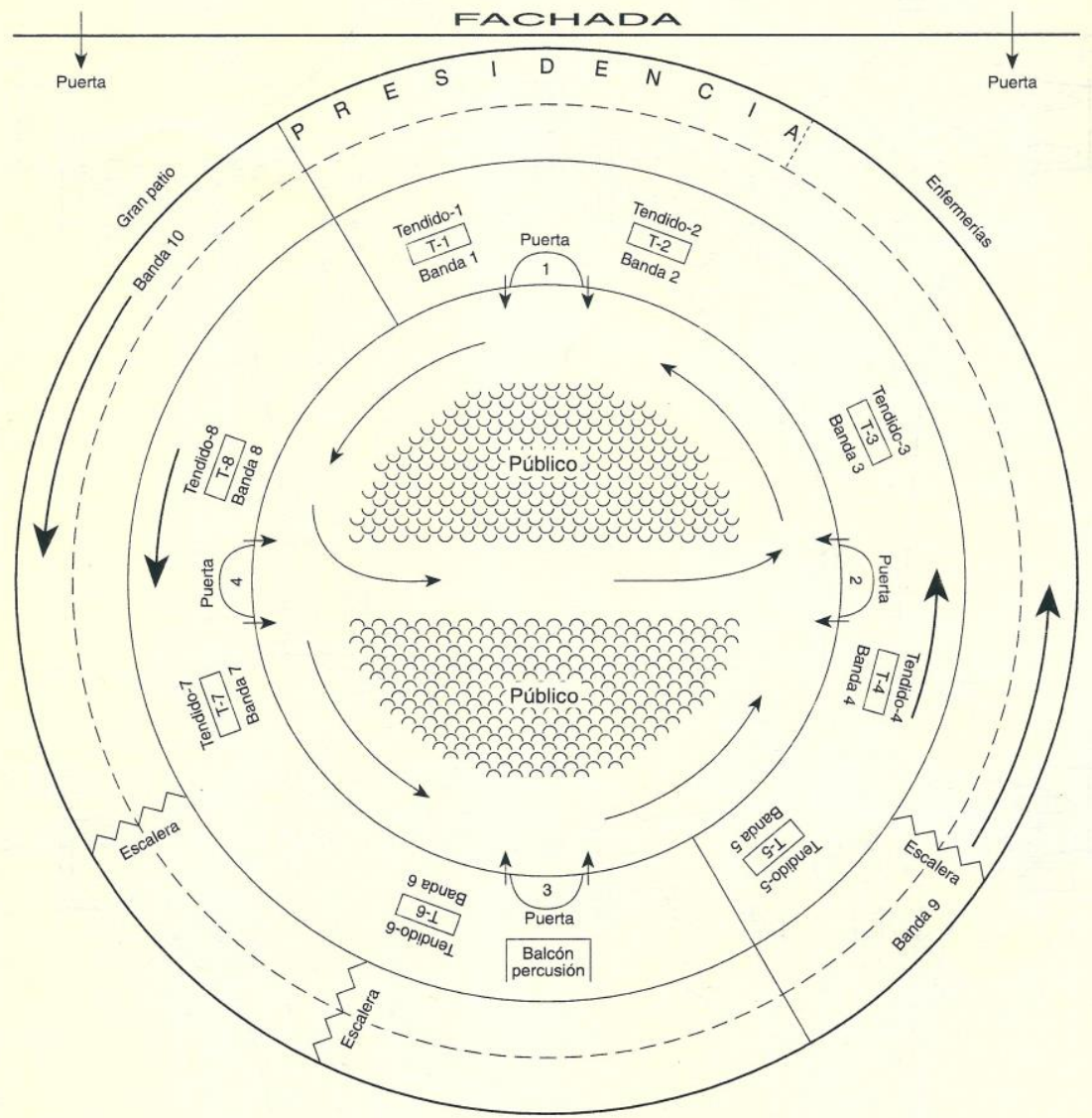

Imagen 6. Llorenç Barber. 1995. Alberomundo.

Algo similar encontramos en Bells and boats (1996), propuesta para la ciudad de Groningen (Holanda). Como en el caso anterior, el compositor describe el movimiento de los focos sonoros, que en este caso son diversos tipos de embarcación (botes y piraguas cargados de campanas y otros instrumentos). La partitura topográfica señala con indicaciones cronométricas la ruta de cada embarcación a lo largo del canal (véase Imagen 7). Como relata el propio compositor,

hasta el extremo del refinamiento fue en Bells and Boats, una música acuática para enorme balsa y docenas de canoas, piraguas, botes $\mathrm{y}$ 
gráciles libélulas, todas ellas preñadas, como no, de campanas, campaneros, y en caso extremo de sopladores de gangosos pitos de pato. Los intérpretes eran como se requería, expertos remeros, algunos olímpicos. Tan atractivo ballet de acercamientos, cruces y deslices tuvo lugar el 9 de agosto de 1996 en Groningen (Holanda), en un ensanche del canal central. (Barber, 2011, p. 2)

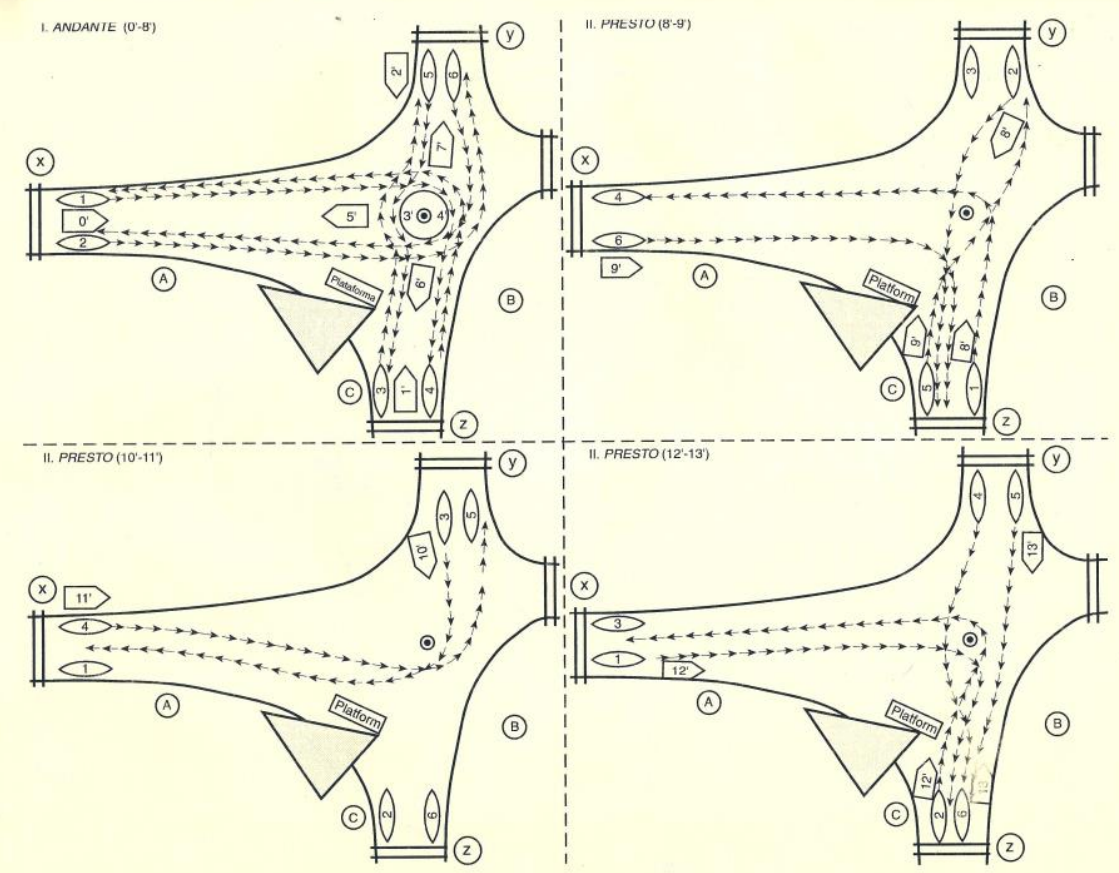

Imagen 7. Llorenç Barber. 1996. Bells and boats.

El segundo tipo de notación es de carácter más tradicional. A diferencia de las partituras de naturaleza topográfica, aquí se indican únicamente los materiales que deben interpretar los músicos en cada momento. Los diversos acontecimientos se indican de manera cronométrica (en minutos y segundos) para facilitar la coordinación entre los diversos foros sonoros. Como en partituras anteriores, es usual el empleo de anillos para permitir la repetición de pequeñas células. De este modo, el compositor emplea técnicas de minimalismo repetitivo para crear grandes masas sonoras micro polifónicas en movimiento (véase Imagen 8). 


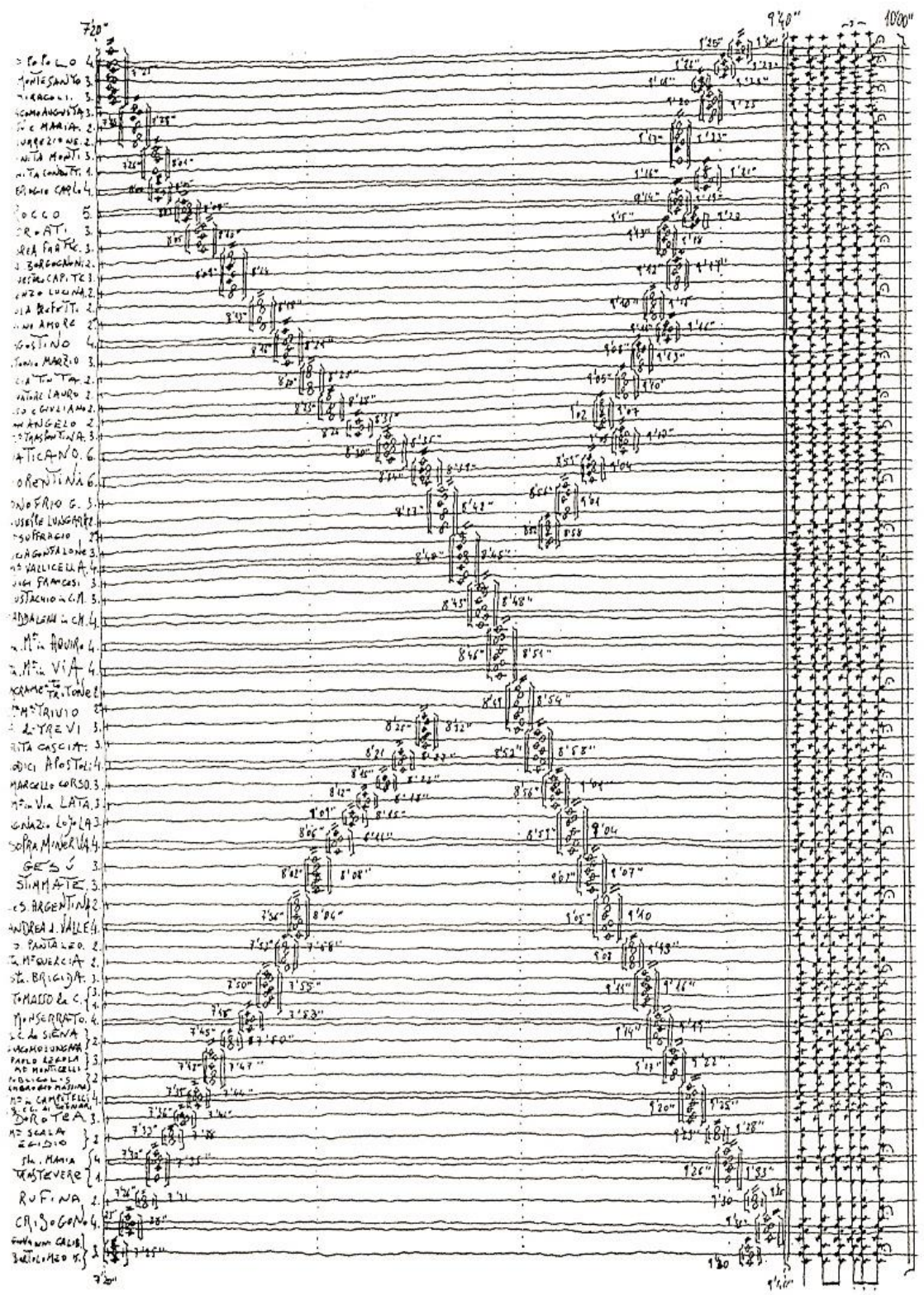

Imagen 8. Llorenç Barber. 1999. Santiago. 
En líneas generales, la escritura musical empleada por Barber para estas enormes composiciones le permite planificar el desplazamiento de los diversos materiales sonoros, así como las texturas resultantes, a lo largo del espacio urbano en marcos temporales dilatados. Como señalan Barber y Palacios (2009), "en el fondo, toda música barberiana de campanarios y ciudades devino reflexión sobre la escritura, o mejor, sobre el escribir el espacio ese que siempre es musical" (Barber y Palacios, 2009, p. 202).

\section{A Modo de Cierre}

Dentro de la producción artística de Llorenç Barber, los conciertos para ciudad representan, tal vez, su apuesta más tenaz y consciente por interrelacionar vida y arte. La liturgia propuesta por el maestro de ceremonias coloca al oyente en una situación de redefinición de su propio contexto cotidiano. En este sentido, las obras de Barber asumen el papel de arte público, aspecto que inevitablemente nos conduce al terreno de lo ético. La vivencia colectiva posibilita escuchar el espacio compartido, al tiempo que refuerza el sentimiento de comunidad. Como indica Álvarez-Fernández (2013),

Es precisamente durante cada una de estas celebraciones cuando estos individuos pueden sentirse y reconocerse como "pueblo", es decir, como miembros de una comunidad inmaterial, vinculados a un propósito común (hacer sonar su espacio, su ciudad; escucharlo, conocerlo, explorarlo, recorrerlo...), y unidos entre sí por una tradición y una memoria (...). (Álvarez-Fernández, 2013, p. 270)

Si reflexionamos sobre qué sentidos y valores pueden generar estas monumentales creaciones, es posible percibir un desplazamiento desde el compositor (cuya función queda diluida en el contexto) hacia cada oyente, como verdadero generador de posibles significados. Una vez que el músico nos coloca fuera del rito tradicional de concierto, es lógico que el oyente tenga ciertas dificultades a la hora de intentar sentido. ¿Cómo afrontar esta nueva situación de escucha? En un concierto de ciudad los acontecimientos sonoros se suceden dentro de un marco temporal fijado, pero difícilmente podemos asegurar cuáles de esos sonidos son "parte de la obra" y cuáles no. Ello nos impide ver claramente cuáles son los propósitos del compositor. Como indica López Cano (1999), en una obra musical tradicional el oyente da por hecho que el compositor manipula el material sonoro para comunicarle algo con un orden y configuración concretos, 
Durante mi ejercicio de receptor hago del autor una hipótesis operativa que (...) esgrimo con la finalidad de garantizar la producción de un sentido musical en la que la ilusión de comprensión ("yo entiendo -o debería entender- lo que el autor me quiere decir") juega un papel fundamental. (López Cano, 1999, p. 6)

Sin embargo, como sucede en el happening, en los conciertos de ciudad no percibimos la articulación de estructuras lógicas con una intención evidente y lineal. En esta disolución del autor, el oyente no puede adoptar una actitud pasiva, pues sus decisiones son importantes (por no decir vitales). ¿Dónde colocarse? ¿Fuera o dentro de la ciudad? ¿Debo estar quieto o puedo pasear? ¿Es preciso prestar atención todo el tiempo? El hecho de hacerse preguntas deja entrever que la obra no es algo que se opone dialécticamente a mi entorno cotidiano, sino que ahora es parte de él. Obra y contexto se confunden, y, como en la vida, el oyente puede construir su propia vivencia estética. De hecho, puede entrar y salir de la obra a su antojo.

Ese dejarse llevar, que permite re-conocer nuestro entorno cotidiano, nos retrotrae inevitablemente a la Teoría de la Deriva de Guy Debord. "Una o varias personas que se entregan a la deriva renuncian durante un tiempo (...) a las motivaciones normales para desplazarse o actuar en sus relaciones, trabajos o entretenimientos para dejarse llevar (...)" (Debord, 1958). Sin embargo, a diferencia de los paseos o derivas de Debord, en los conciertos de Barber existe una dimensión ceremonial donde lo colectivo y lo lúdico se entretejen en una redefinición del contexto público. Los conciertos de cuidad suponen intervenir artísticamente el espacio común para devolverlo a la comunidad en forma de fiesta y celebración de lo colectivo. Una vez más, ello evidencia un compromiso ético. La propia mutación del compositor a nuevo papel como "propositor" (facilitador de procesos), lo evidencia. Como concluye García (2013),

Finalmente, la figura del autor se diluye. El compositor queda camuflado detrás del campo de posibilidad propuesto. Como si de un maestro de ceremonias se tratase, ofrece esta música urbana para el ejercicio libre del ciudadano en la ciudad, estableciendo un marco organizativo capaz de orientar esta multiplicidad de relaciones potenciales. Notamos así una traslación de la noción individualista compositor-genio, hacia un entendimiento del artista como agente social, como director de escena en buscar de una transformación útil de los hábitos perceptivos de la comunidad, como movilizador social de sentidos y sensibilidades, de tiempos y espacios nuevamente significativos. (García, 2013, p. 158) 
Así, frente a la noción romántica del compositor como generador de estructuras atemporales, Llorenç Barber, desde un profundo convencimiento ético, asume su rol como artista comprometido con su contexto. Sus intervenciones sonoras en espacios cotidianos nos recuerdan insistentemente la frágil y artificiosa separación entre la vida y el arte. En este sentido, las obras de Barber son posibles respuestas, no exentas de pensamiento utópico, acerca de las preguntas que nos planteábamos al comienzo de este texto.

\section{Referencias}

Álvarez-Fernández, M. (2013). ¿Por quién doblan las campanas? Llorenç Barber y Monteserrat Palacios: sonidos desde el umbral entre dos paradigmas creativos y sociales. En 100 años de Arte Sonoro Valenciano (1912-2012). (pp. 268-280) Valencia: Universidad Politécnica de Valencia.

Arroyave, M. (2013). La construcción racional del tiempo en la música escrita de la tradición occidental. Cuadernos de Música, Artes Visuales y Artes Escénicas, 8 (1), 87-101.

Barber, L. (1985). John Cage. Madrid: Círculo de Bellas Artes.

Barber, L. (1997). Una tarea compositiva: sonar ciudades. Humboldt. Inter Nationes, 121, 28-30.

Barber, L. (2011). Las naumaquias o sobre la música hecha agua y otras liquidaciones". II Encuentro Iberoamericano sobre Paisajes Sonoros. Centro Virtual Cervantes. Recuperado de http://cvc.cervantes.es/artes/paisajes_sonoros/p_sonoros02/barber/ba rber_01.htm

Barber, L., Palacios, M. (2009). La mosca tras la oreja. De la música experimental al arte sonoro en España. Madrid: Fundación Autor.

Buj Corral, M. (2015). Partituras Gráficas: Entre el Tiempo y el Espacio. BRAC - Barcelona Research Art, Creation, 2(3), 277-300.

Cage, J. (1961). Silence. Cambridge: Wesleyan University Press.

Debord, G. (1958). Teoría de la deriva. En II International Situationista, vol. I. La realización del arte. Madrid: Literatura Gris, 1999. Recuperado de:

www.ugr.es/ silvia/documentos\%20colgados/IDEA/teoria\%20de\%2 0la\%20deriva.pdf

García Sánchez, M. T. (2011). De la ciudad en vibración al ser resonante. Una investigación a propósito de los conciertos de campanas de Llorenç Barber. (Tesis Doctoral). Universidad Politécnica de Madrid, 
2011.

Recuperado

de: oa.upm.es/12786/1/MARIA_TERESA_GARCIA_SANCHEZ_1.pdf

García Sánchez, M. T. (2013). Sonar ciudades: una lúcida de lo urbano. AUSART Journal for Research in Art, Universidad del País Vasco, 1 (1), 155-160.

Huizinga, J. (2005). El otoño de la Edad Media. Trad. esp. José Gaos y Alejandro Rodríguez de la Peña. Madrid: Alianza Editorial.

López Cano, R. (1997). Música plurifocal: Conciertos de ciudades de Llorenç Barber. Méjico: JGH Editores. Bibliotheca Litterarum Humaniorum IV. Colección Euterpe.

López Cano, R. (1999). El compositor in fabula, el receptor confuso y el músico verdadero. En L. Barber (Ed.) O Roma Nobilis, (pp. 3-14). Valencia: Generalitat, 3-14.

Nyman, M. (2006). Música experimental. De John Cage en adelante. Girona: Serie conTmpo, Documenta Universitaria.

Pardo, C. (1999). Escritos al oído. Murcia: Colección de Arquitectura 38.

Paynter, J. (1999). Sonido y estructura. Madrid: Ediciones Akal.

Schafer, M. (2013). El paisaje sonoro y la afinación del mundo. Barcelona: Intermedio.

Schloezer, B, (1961). Introducción a Juan Sebastián Bach. Ensayo de estética musical. Buenos Aires: Editorial Eudeba. Editorial Universitaria de Buenos Aires.

Tzara, T. (1922). Lectures on Dada. En R. Motherwall (Ed.), Dada Painters and Poets: An Anthology (Ed.). Boston: Cambridge, Mass, Belknao Press of Harvard University Press.

Xenakis, I. (1982). Música. Arquitectura. Barcelona: Antoni Bosh Editor. 
Isaac Diego García Fernández: Doctor en Musicología. Profesor de la Facultad de Educación de la Universidad Internacional de La Rioja.

Email address: isaacdiego.garcia@unir.net

\section{Web:}

https://universidadinternacionaldelarioja.academia.edu/IsaacDiegoGarc\%C3 $\% \mathrm{ADa}$

Contact Address: Facultad de Educación, Universidad Internacional de La Rioja. Av. de la Paz, 137, 26006 Logroño, La Rioja. 